Copyright $\odot$ SAGE Publications 2007 (Los Angeles, London, New Delhi and Signapore) 1468-7968

Vol 7(3):390-415;080235

DOI: $10.1177 / 1468796807080235$

http://etn.sagepub.com

\title{
Old and new inequalities in educational attainment
}

\section{Ethnic minorities in the Belgian Census 1991-2001}

\author{
KAREN PHALET \\ Universities of Utrecht and Leuven, Belgium
}

\section{PATRICK DEBOOSERE}

Free University of Brussels, Belgium

\section{VICKY BASTIAENSSEN}

Free University of Brussels, Belgium

\begin{abstract}
This study examines ethnic and class inequalities in educational attainment using the 2001 Belgian Census. It analyses the highest qualifications that the 1973 to 1979 birth cohort obtained in 2001. Variation in attainment levels is explained as a function of gender, ethnic and class origins, and other characteristics of the parental household in 1991. Earlier findings of gross ethnic disadvantage, in particular among Turkish and Moroccan youngsters, were largely replicated when ethnicity is identified by ancestry rather than nationality. Looking across ethnic groups, parental resources in 1991 were very powerful predictors of educational attainment in 2001. In order of importance, parental education, accumulated wealth (as measured by ownership and quality of housing), employment and occupational class explain most educational inequality. Ethnic disadvantage is perpetuated from one generation to the next mainly through mechanisms of class disadvantage. In addition, there is evidence of cumulative ethnic and class disadvantage for Turkish and Moroccan minorities. Finally, the largest unexplained ethnic disadvantage is found for the Turkish minority in Flanders. Not only are they most underrepresented in tertiary education, they are also most at risk of school dropout in secondary education.
\end{abstract}

KEYWORDS educational inequality $\bullet$ ethnic disadvantage $\bullet$ ethnicity $\bullet$ second generation $\bullet$ social class 


\section{INTRODUCTION}

Earlier research on educational inequality found evidence of ethnic advantage as well as disadvantage when minority groups are compared to a non-minority reference group with a similar social-class background (see for example Alba et al.,1994; Vallet and Caille, 1996). This study examines ethnic inequalities in educational attainment using the most recent 2001 Belgian Census. Specifically, it analyses the highest qualifications that the 1973 to 1979 birth cohort obtained in 2001. Variation in attainment levels is explained as a function of gender, ethnic and class origins, and other relevant characteristics of the parental household in 1991. The data consist of one in 10 random samples of linked and anonymized records of ethnic origin groups from the 1991 and 2001 Censuses. This longitudinal dataset allows us, for the first time ever in Belgium, to identify key demographic, socioeconomic and ethnic characteristics of parental households and to estimate their effects on the educational attainment of the next generation.

The aim of our study is primarily descriptive. The descriptive analysis establishes the nature and sizes of ethnic differences in educational attainment. In addition, multinomial logistic regressions formally test how much of the total variation in attainment levels in 2001 is explained by relevant characteristics of parental households in 1991. Net ethnic differences in educational attainment are estimated by the effect sizes of ethnic origins after taking into account the social class background of minority families. In technical terms, a positive ethnic effect is interpreted as evidence of ethnic advantage, so that members of an ethnic minority are doing better relative to the non-minority reference population than would be expected on the basis of their social class origins. By contrast, a negative effect suggests cumulative ethnic and class disadvantage. Cumulative disadvantage implies that the less advantaged social class background of ethnic minority families explains only part of the educational disadvantage. Last, nonsignificant or zero ethnic effects would mean that ethnic equals class disadvantage, in which case parental class disadvantage fully accounts for the educational disadvantage of members of an ethnic minority. Importantly, this simple additive model of ethnic and class disadvantage should be qualified in at least two ways. First, the meaning of class origins differs between migrant workers and the native working classes, because of distinct class structures in rural sending regions and selective out-migration. Second, the class position of ethnic minorities in the receiving society is, at least to some extent, a consequence of their ethnic minority status. Hence, rather than postulating the causal primacy of class origins, we prefer to think of social class in terms of the mediating mechanisms behind the transmission of disadvantage from one generation to the next.

Accordingly, most sociological research on class disadvantage has 
documented and explained the relative persistence of educational inequality across generations (Shavit and Blossfeld, 1993). In complete contrast, a strong research tradition on immigrant integration in the USA finds evidence of intergenerational progress, with the next generation achieving on a par with, or even outperforming, their non-minority peers (Alba and Nee, 2003). Looking beyond the recurrent class versus ethnicity debate in migration studies, this study examines the role of parental resources and resource investment in minority and non-minority workingclass families. At the household level, macro relationships of socioeconomic exploitation or ethnocultural exclusion can be defined by the unequal access of families to resources. Taking a perspective from resource investment theory, then, both ethnicity and class refer to categories of families accumulating bundles of resources, and investing (part of) them in the next generation.

Furthermore, we distinguish between material wealth or 'capital' proper and other types of resources known as human capital and social or cultural capital. While few sociologists would deny that parents' non-material resources make a difference in the life chances of their children, these types of resources seem all the more important in the analysis of ethnic differences (Modood, 2004). Indeed, migration and ethnic group formation are usually related to differences in cultural resources, such as language (Chiswick and Miller, 1998). Interestingly, sociologists adopting an approach from class analysis associate ethnic diversity with deficits in various sorts of family-based resources (Kalmijn and Kraaykamp, 1996; Lareau and MacNamara Horvat, 1999). Conversely, American sociologists have focused more on ethnicity as a resource, linking intergenerational integration to the mobilization from below of 'ethnic' resources (Portes and Zhou, 1993; Zhou and Bankston, 1998). This study addresses the key question: Which family-based resources are hindering or helping the children of migrant workers to stay on in school and to obtain higher qualifications?

At the empirical level, the analysis reflects on some unanswered questions regarding the forms and causes of educational inequality in Belgium. Recent research on the Organisation for Economic Co-operation and Development's (OECD) 2000 PISA (Program of International Student Assessment) data has shown that ethnic minority children in Belgium are lagging behind in mathematics and reading skills. Moreover, achievement gaps for the second generation in Belgium were among the largest compared to those in other OECD countries (Marks, 2006). In Belgium, ethnic minorities are over-represented in vocational training and underrepresented in general and higher forms of education (Ouali and Réa, 1994; Neels, 2000). They are also more often failing exams, repeating class, and leaving school without qualifications (see Phalet and Swyngedouw, 2003 for a review). However, a common limitation of these studies is that they use 
nationality rather than the ethnic origin of the parents to identify ethnic minorities. Hence, the analyses and findings do not fully cover the second generation, i.e. the offspring of immigrant workers in Belgium, as distinct from the first generation of immigrants proper. Moreover, previous studies did not usually include complete school careers, nor did they use longitudinal data to test competing explanations of differential attainment formally.

This study therefore adds to the existing research in various ways. It examines to what extent the known educational disadvantage of immigrants persists across generations, when the second generation with an ethnic minority background is properly identified. Our study also improves on previous studies by using most recent data on the attainment of minority and non-minority young adults in the age range of 22 to 28 when almost all have completed their education. As Neels (2000) nicely showed by estimating dynamic models of expected school careers, right-censored data on the observed school careers of relatively young minority populations in Belgium tend to underestimate their final educational attainment. Consequently, earlier findings of gross educational disadvantage may present an overly pessimistic picture of their final qualifications. Most importantly, this study is the first in Belgium to test competing explanations of educational inequality in terms of ethnic and class origins, using parental data in representative samples of minority and non-minority populations.

\section{ETHNIC MINORITIES IN BELGIUM}

Up until the First World War, Belgium was an emigration country. Ever since the 1920s, however, the country has known a positive migration balance. Early migrant workers came from the neighbouring countries and from central and southern Europe, in particular from Poland and Italy. While the economic recession of the 1930s and the Second World War put an end to the early recruitment of foreign workers, the expanding heavy industries in the 1950s attracted significant numbers of new immigrants as so-called guest workers. From the 1960s onwards, migration statistics show a large and steady intake of foreign labour. The first wave of post-war guest workers was of southern European, mainly Italian origin. In the late 1960s, the recruitment of foreign labour expanded around the Mediterranean, including Turkey and Morocco.

In the late 1970s and early 1980s, the international oil crisis, the closing of the coalmines, and the rapid decline of heavy industry marked the transition to a post-industrial economy. As most immigrants in Belgium were employed in the industrial sector, the immigrant populations were disproportionately affected by economic restructuring, which entailed 
massive and enduring unemployment and economic inactivity among the first generation. Yet, unlike the 1930s, there was no significant dip in the immigration statistics of the 1980s. Instead, family reunification and family formation became the main sources of continuing immigration. This change in the nature of immigration resulted in the permanent settlement of immigrant families and communities in Belgium. Since the 1990s, the second generation of immigrant origin are leaving school and entering the labour market in increasing numbers. At the same time, immigration from Morocco and Turkey continues today, mainly through cross-border marriage.

Although the new immigration is increasingly diversified, including undocumented workers, refugees, asylum seekers, students and professionals, both from within and outside the EU, it is noteworthy that Belgium has never known a significant post-colonial migration. Importantly, recent legislative changes have enhanced the access of immigrants and their offspring to Belgian citizenship, causing a marked decline in the size of the foreign population. Already in 1991, one in four residents of foreign origin were no longer counted as foreigners (Eggerickx et al., 1999). As can be seen from Table 1, foreign nationality categories in the most recent 2001 Census have become entirely inadequate to identify young adults of immigrant origin.

Table 1 shows the ethnic minority populations included in this study, i.e. young adults of Italian, Moroccan, Turkish, other or mixed migrant origin, as well as a reference population of non-migrant origin. Taken together, over 17 percent of the young adult population in the 2001 Census is of migrant origin. The Italian (2.6\%), Moroccan $(2.8 \%)$ and Turkish origin groups $(1.5 \%)$ are the largest minorities in Belgium, not counting immigration from the neighbouring countries. The latter are combined with other source countries into a residual category.

As criteria to identify ethnic ancestry, we used the nationality at birth of both parents. For example, if one's mother and father had Turkish nationality at their own birth, one is categorized as Turkish, regardless of one's own country of birth or nationality at birth. ${ }^{1}$

A majority of young Italians, Moroccans and Turks are second generation, i.e. they are the local-born children of migrant parents. While three in four Moroccan and Turkish young adults are second generation, almost all Italians are local born and about one in four is third generation, i.e. they have at least one local-born parent of migrant origin. Accordingly, most Moroccan and Turkish youngsters, as well as one in two Italians, are Belgian citizens. Note that national origin, i.e. one's nationality at birth as distinct from one's current nationality in the 2001 Census, is no longer sufficient to identify the second generation, because it excludes ethnic minority youth who are born as Belgian citizens (11\% of Moroccans, $15 \%$ of Turks, and $20 \%$ of Italians.) 


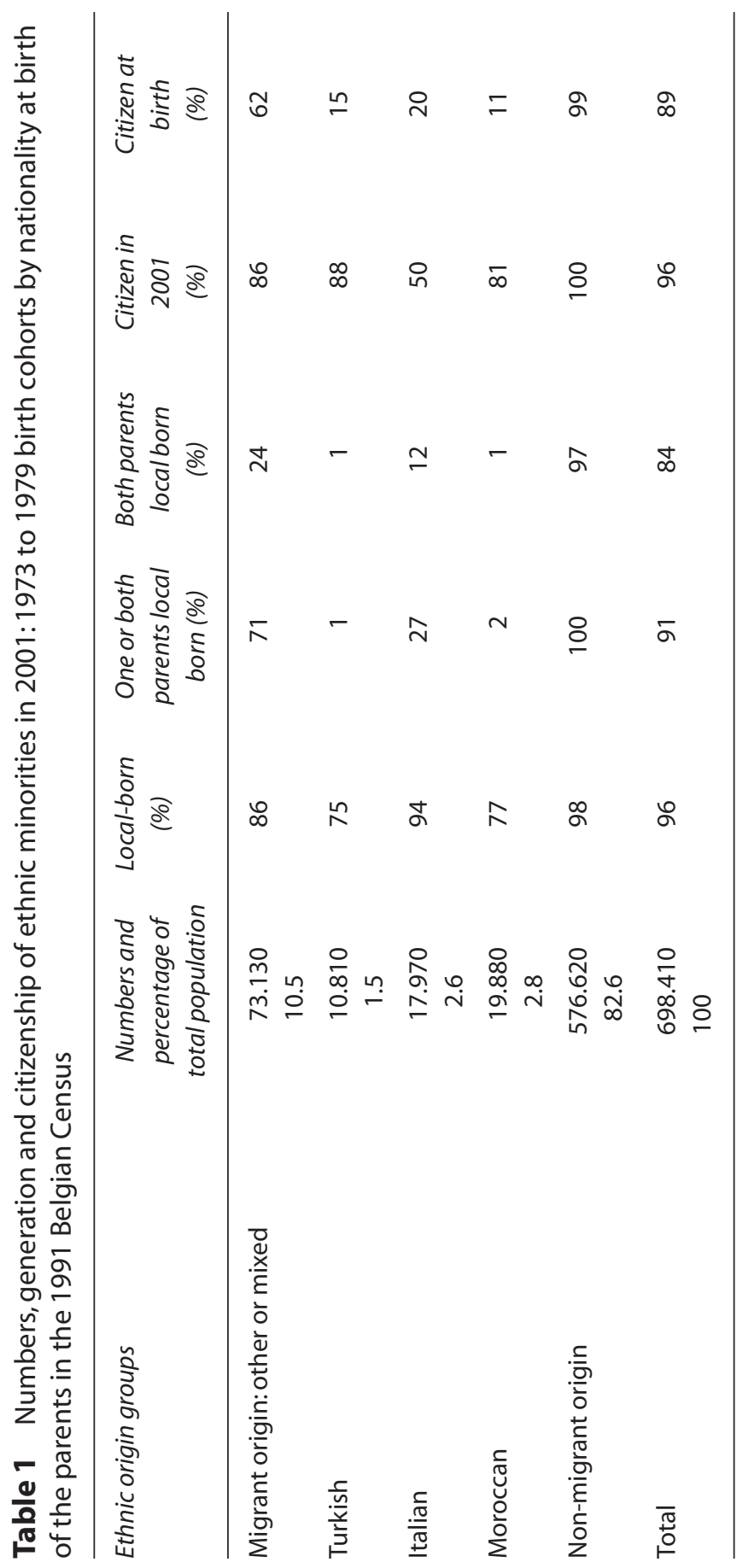


This study compares young adults of different ethnic origins within a narrow age range. Specifically, the 1979 cohort was taken as a lower boundary, because it has just reached the theoretical age of graduation (at age 22) in the 2001 Census. Similarly, the 1973 cohort was taken as an upper boundary, because it has just reached the age of 18 in the 1991 Census, when compulsory education is completed and when students make the critical transition to tertiary education or to the labour market. Another consideration is that the identification of ethnic origin, in the absence of direct census questions on ethnic ancestry, is only possible for those persons who were still living with their parents in the previous 1991 Census. Above the age of 18 , increasing percentages are leaving the parental household, so that the inclusion of older cohorts would induce increasing selection bias.

\section{THE BELGIAN EDUCATION SYSTEM}

The education systems in the French- and Dutch-speaking parts of Belgium have a common hierarchical tracking structure, with increasingly specific vocational tracks throughout lower and upper secondary and tertiary levels. A first branching point is the transition from primary to lower secondary school, which occurs at the theoretical age of 12 . At this point, students are divided between a higher and a lower track, the latter giving access to vocational training only. At age 14, students are selected further into three types of tracks at the upper secondary level: the academic track preparing for university, the middle-level tracks preparing mainly for professional types of higher education, and the full-time or part-time vocational tracks that lead to the labour market, either directly or after one or more years of post-secondary specialization. At the theoretical age of 18, schooling is no longer compulsory for students with at least lower secondary qualifications. Those who stay on in school can make the transition to tertiary education. This transition constitutes another branching point, when students may enter an academic type or else an advanced professional type of tertiary education. Our measure of educational qualifications therefore distinguishes the following categories:

- higher tertiary: university degree;

- lower tertiary: professional education;

- upper secondary: academic;

- upper secondary: middle-level;

- upper secondary: vocational;

- lower secondary; and

- primary or none. 
However, common tracking structures in different parts of the country do not imply similar tracking practices. Thus, in comparison with students in the Dutch-speaking school system, students who fail their exams in Frenchspeaking schools are more often repeating class and less often reoriented 'downward' towards vocational tracks (Ouali and Réa, 1994). In light of more frequent school failure among ethnic minorities, tracking practices in French-speaking schools should allow more minority students to continue their education in the academic track and to enter university. On the other hand, downward reorientation in Dutch-speaking schools avoids delays and reduces the numbers of minority students who leave school without full secondary qualifications at the age of 18 . To account for differential tracking practice, the analysis of educational attainment controls for region of residence in 1991. Thus, we estimate the impact of attending secondary school in French-speaking Wallonia, in the officially bilingual though mostly French-speaking region of Brussels, or in Dutch-speaking Flanders.

\section{FAMILY-BASED RESOURCES AND EDUCATIONAL ATTAINMENT}

Most research on intergenerational mobility has focused upon the economic role of the father as the main determinant of social class origin. The assumption that the social class status of the family depends solely on the husband-father, however, has been questioned and alternative approaches to class have been developed. Following Britten and Heath (1983), Rothon (2005; see also this issue) develops a schema where the parent whose socioeconomic attainment is dominant tends to outrank the other. Such an approach may be particularly useful in explaining educational attainment across ethnic groups, since gender roles vary with ethnicity. Moreover, in research on educational aspirations and educational support in minority families, women seem to play a key role (Feliciano and Rumbaut, 2005). Accordingly, this study uses a social class schema that takes into account the social class of both parents.

Our primary measure of social class is based on the labour market participation of one's mother and father in 1991. Thus, economically inactive or unemployed parents are distinguished from employed or self-employed parents. Parents who were (self)employed in 1991 are subdivided into broad occupational classes by combining categories into the 'salariat' (professional and managerial occupations), intermediate (skilled non-manual and manual occupations together with the self-employed and small employers) and working classes (semi- and unskilled manual occupations). In line with the dominance approach, the educational attainment of the child does not differ significantly once the class of the parent whose labour market participation 
was dominant in 1991 is taken into account. When one parent was absent from the household in 1991, or when data on one parent are missing, the single parent, or the parent for whom data are available, determines the class origin of the child. Thus, we arrived at a fourfold class schema:

- salariat: at least one parent in professional or managerial occupations;

- intermediate class: at least one parent in routine non-manual or skilled manual occupations, or working on his/her own account; the other parent in similar occupations, or in semi- or unskilled manual work, or not working;

- working class: at least one parent in semi- or unskilled manual work; the other parent in similar manual work or not working;

- not working: both parents, or a single parent, unemployed or economically inactive.

To account for the possible impact of incomplete or single-parent families on the children's school careers, the presence of both parents in the household in 1991 was included as a demographic control variable.

In addition, the educational qualifications of the parents are also measured. Parental education is included as a parsimonious proxy for family-based human capital as well as cultural capital. One should bear in mind, however, that the qualifications of immigrant parents were obtained in the country of origin. Hence, they do not denote relevant cultural capital - in the Bourdieuian sense of the cultural repertoire of the dominant classes - to the same extent as the qualifications of non-migrant parents do. Even human capital in the narrow sense of educational credentials and work experience is to some extent anchored in local careers (Chiswick and Miller, 1998). In view of the restricted convertibility of migrant resources and the ensuing adaptation problems of recent migrants, the timing of parental migration is added as a control variable. Our measure of parental education is based on the parent with the highest qualifications in 1991. It combines International Standard Classification of Education (ISCED) codes to derive four nominal categories:

- at least one parent with tertiary qualifications;

- at least one parent with upper secondary qualifications; the other parent has similar or lower qualifications;

- at least one parent with lower secondary or primary qualifications; the other parent with similar qualifications or none;

- both parents, or a single parent, without formal qualifications.

In addition to the occupational and educational status of the parents, the housing conditions of the family in 1991 serve as an index of material 
wealth. Given the incomplete and often unreliable nature of self-reported earnings as an indicator of current family income, the quality and ownership of housing provide a more efficient estimate of accumulated wealth. If educational choices are seen as decisions about a family's financial investment in the future, youngsters from wealthier families should be more likely to stay on in school after compulsory education (Boudon, 1974). In addition, it has been argued that even small differences between families in material resources can have cumulative consequences for the life chances of the children (Esser, 2004). Regardless of parents' education and current occupation, financial resources may determine, for instance, whether one's family can afford living close to good schools or having a quiet room to study at home. Indirectly, then, financial resources can be decisive for the accumulation of other kinds of relevant resources, such as affinity with high culture (such as books, beaux arts participation) or strategic social ties. The housing conditions of the parental household in 1991 were measured by four nominal categories, which were found to predict other correlates of economic wealth, such as life expectancy, more reliably than self-reported earnings:

- rented housing of low quality;

- rented housing of middle-level or high quality;

- own housing of low quality;

- own housing of middle-level or high quality.

\section{ETHNIC DIFFERENCES IN EDUCATIONAL ATTAINMENT}

To begin with, the highest qualifications of young adults in 2001 are examined, cross-tabulated by ethnic ancestry (see Table 2 ). ${ }^{2}$ Looking across educational levels and types, the largest ethnic gap is found in the percentages getting university degrees at the top and falling short of full secondary education at the bottom end of the attainment range. By contrast, the middle-level type of upper secondary education, teaching technical professions and the arts, does not vary with ethnicity.

In examining ethnic differences in attainment, a clear ethnic hierarchy is apparent. Turks are most under-represented in tertiary forms of education but are over-represented in vocational training at the upper secondary level. And they are the most likely to leave school with less than full secondary qualifications. Not only are they six times less likely than their nonminority counterparts to have a university degree (3\% against 18\%), they are almost three times more likely to have less than full secondary qualifications (36\% against $13 \%)$. Even if they complete full secondary education, 


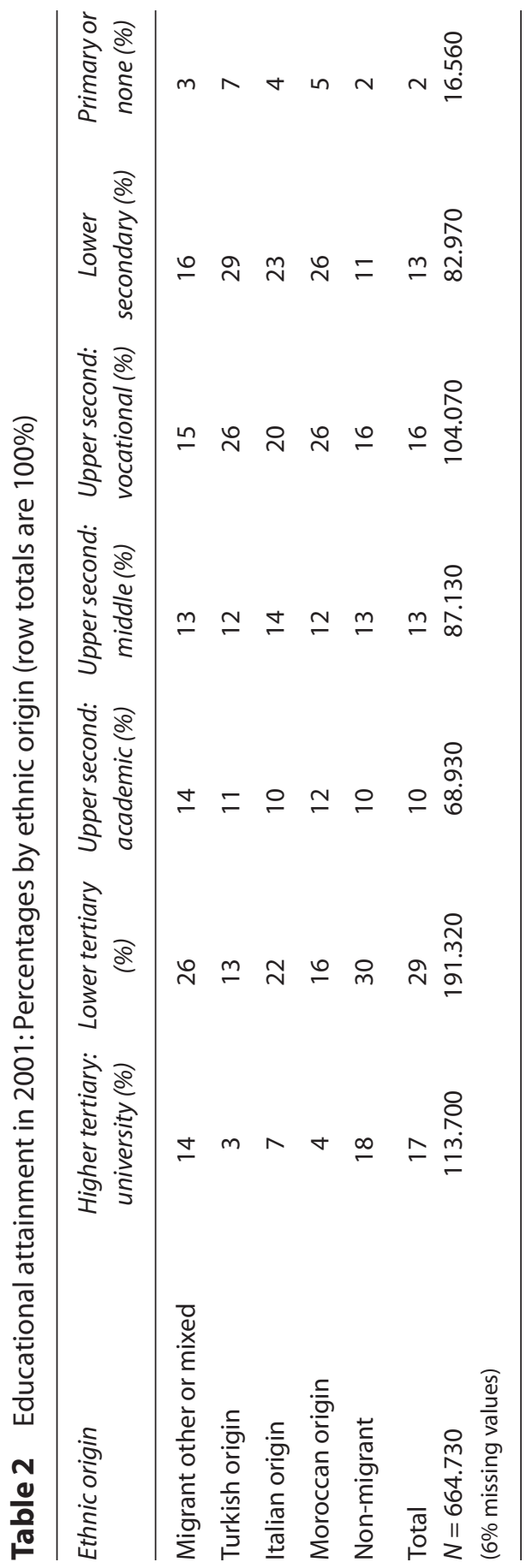


they are still one and a half times more likely to follow vocational rather than middle-level or academic tracks (26\% against $16 \%)$.

Moroccans are only slightly less disadvantaged than Turks. By comparison, Italians are about twice as likely as Turks or Moroccans to have tertiary qualifications and they less often leave school without full secondary qualifications. Yet, Italians are still at a disadvantage compared to their non-minority peers: the latter are more than twice as likely to have a university degree (18\% against $7 \%$ ), while the former are twice as likely to have less than full secondary qualifications (27\% against $13 \%)$. The residual category of other or mixed origin achieves almost on a par with the reference group of non-migrant origin, which exhibits the highest level of attainment. This pattern of overall ethnic disadvantage replicates earlier findings on the educational attainment of ethnic minorities in Belgium.

As a complement to the descriptive results, Tables A1 and A2 in the Appendix show the results of multinomial logistic regressions. These regressions estimate the odds of attaining either higher qualifications (i.e. the academic type of upper secondary, lower or higher tertiary) or lower qualifications (i.e. the vocational type of upper secondary, lower secondary or less) relative to middle-level full secondary education (the reference category). In the most simple baseline model, ethnic origin was entered as a predictor of attainment in 2001, along with one's gender and age and the region of residence in 1991. In subsequent models, we tested the role of various kinds of parental resources in 1991 as explanatory variables. The parameter estimates in Table A2 show the final regression model, which estimates the main effects of all explanatory variables simultaneously.

As evident from the significant effects of gender in Table A2, ethnic differences coexist with a cross-ethnic gender gap in attainment. In line with international findings (e.g. Rothon, 2005), women outperform boys at both the secondary and tertiary levels of education. Thus, girls are more inclined than boys to follow academic tracks and to stay on in tertiary education. And they less often leave school without full secondary education. In the absence of a significant gender by ethnicity interaction, girls with an ethnic minority background show the same relative educational advantage as their non-minority counterparts.

In spite of repeated findings of delayed attainment in ethnic minority groups (Neels, 2000), the age effects show the same linear trend in increasing attainment across ethnic groups. With every added year beyond the theoretical age of completion at 22 , more students obtain tertiary qualifications. Even the rates of completing secondary and entering tertiary education show some further increases with age above 22. In the absence of significant age by ethnicity interaction terms, most young adults with an ethnic minority background seem to have caught up with non-minority students. Hence, there is no reason to expect a narrowing of the ethnic gap 
in attainment if we were to follow up the same cohorts of minority and non-minority students after 2001.

There is also the issue of regional discrepancies in tracking practices, which might disproportionately affect the school careers of minority students. To test regional differences in attainment, we compared Dutchspeaking Flanders and French-speaking Wallonia with the bilingual region of Brussels as a reference, while controlling for the differential composition of the student population across regions. The pattern of regional effects closely reflects known differences in tracking practices between Dutch- and French-speaking schools. Thus, students in French-speaking schools (i.e. in Wallonia) are less often oriented towards vocational training. Instead, they more often continue in the academic track and make the transition to tertiary education. Conversely, students in Dutch-speaking schools (i.e. in Flanders) are less likely to obtain academic or higher qualifications. At the same time, they less often repeat class or leave school without full secondary qualifications. Apparently, Dutch-speaking schools are more efficient in avoiding school dropout, whereas French-speaking schools are more inclusive in giving access to higher education. Significant region by ethnicity interaction terms suggest that, ceteris paribus, ethnic minorities in Flanders are least likely to obtain university degrees or other types of higher qualifications.

\section{TESTING THE EXPLANATORY ROLE OF PARENTAL RESOURCES}

Five models are estimated to test the effects of different kinds of parental resources on the educational attainment of their children. The explanandum is the highest qualification of the child in 2001. The first model includes only ethnic origin, gender, age and region as predictors of attainment. The second adds social class origin, the third model adds the educational qualifications of the parents and the fourth model adds parental housing (all measured in 1991). The fifth adds controls for the timing of parental migration and the presence of both parents in 1991. As Table A1 shows, each model significantly improves the fit and the final model explains about 28 percent of the total variation in qualifications. By contrast, Model 1 with ethnicity and gender only explains 8 percent of the variance. Adding parental occupations and qualifications in Models 2 and 3 increases the explained variance significantly, by 11 percent and 7 percent respectively. In Model 4, the housing index of wealth adds another 2 percent.

When all parental resources have been added in the final model, ethnicity still contributes significantly to the explanation of educational attainment (see Table A2). Overall, this finding suggests that the 
educational disadvantage of ethnic minorities is due to cumulative ethnic and class disadvantage. A closer look at the ethnic coefficients, however, adds some qualifications to the cumulative disadvantage hypothesis. Thus, the educational disadvantage of Italians is fully explained by the generally less advantaged social-class background of Italian migrant workers. In the Italian case, then, ethnic disadvantage equals class disadvantage. By comparison, both Turks and Moroccans experience some degree of additional ethnic disadvantage, which cannot be explained by their family background. Both Turks and Moroccans are less likely to get university degrees than others with similarly disadvantaged social backgrounds. Turks are also significantly under-represented in other types of tertiary education; and they are over-represented among school leavers with less than full secondary qualifications. We will come back to this 'Turkish disadvantage' later. Importantly, there are no positive ethnic coefficients. Contrary to the ethnic advantage hypothesis, ethnic minorities in Belgium are at best achieving only on a par with their non-minority counterparts.

To test formally whether parental resources work in the same way for ethnic minority as for non-minority students, the interactions of each predictor with ethnicity are also estimated. With few exceptions, the differences in chi-squared values between the complete model with and without an interaction term indicate no significant improvement in model fit. In line with British findings (Rothon, 2005), the absence of significant interactions suggests that social class influences the school careers of ethnic minority and non-minority students in much the same way. The only exceptions to the rule are the effects of region and housing, which do vary significantly between ethnic groups. Thus, the ethnic gap between minority and non-minority attainment levels is even larger in Flanders than in Brussels or Wallonia. Furthermore, home ownership is associated with less educational advantage in ethnic minority families than in non-minority families.

As can be seen from Table A2, the educational credentials of one's parents contribute most to the overall fit of the final model. Children whose parents have a university degree or at least full secondary education are themselves more likely to have obtained academic secondary or tertiary qualifications. Conversely, children whose parents have no formal qualifications are most likely to leave school with vocational secondary or lower secondary qualifications. In the absence of significant interactions with ethnicity, it seems safe to conclude that the education of migrant parents is decisive for the attainment of the next generation. Apparently, education matters even though most migrant parents obtained their qualifications abroad. Moreover, the timing of the parents' migration has only small or non-significant effects on the second generation. These findings offer little support for the assimilation hypothesis, which predicts that length of 
residence reduces initial restrictions on the convertibility of foreign human capital, for instance due to language barriers (Chiswick and Miller, 1998). It should be borne in mind, however, that most migrant workers brought little human capital with them; and the harsh working conditions of the first generation were hardly conducive to the acquisition of new knowledge and skills.

Next most important in size is the impact of material wealth, based on the housing conditions of one's family in 1991 (Table A2). Children whose families rented low-quality housing are most disadvantaged in contrast with children whose parents owned middle- or high-quality housing: the former are least likely to have university or other tertiary qualifications; and they are most likely to leave school with vocational or lower qualifications. Importantly, the pattern of housing effects reveals that some educational advantage is attached to ownership, even in the case of low-quality housing. However, significant housing by ethnicity interactions indicate that home ownership benefits ethnic minorities less. We can only speculate why this would be the case. Since the housing index takes into account quality of housing, the fact that minority families more often own low-quality houses cannot explain the interaction.

In the third place, the occupational class of the parents also explains an important part of the variation in educational attainment. In parallel with British findings (Rothon, 2005; see also this issue), children who had at least one parent in the salariat in 1991 appear to be most advantaged in comparison with working-class children: they are the most likely to have university degrees in 2001 and are least likely to have vocational or lower qualifications. In addition, having at least one parent in the intermediate classes significantly improves one's chances to avoid leaving school with vocational or lower qualifications later on. Last, parents without work have much the same impact on their children's later attainment as working-class parents, with one exception: when parents do not participate at all in the labour market, their children are even less likely to go on and successfully complete university education than if one or both parents are semi- or unskilled workers. Finally, it is noteworthy that children from single-parent households are not consistently more disadvantaged in school than children with complete families in 1991, once the social class background of the parents has been taken into account. In the absence of significant interactions, the occupational class of the parents influences the school careers of ethnic minority and non-minority students in similar ways. In light of the predominant working-class profiles of Turkish, Moroccan and Italian parents, and very low levels of labour market participation, we conclude that class disadvantage plays an important role in perpetuating ethnic disadvantage across generations (Phalet, 2007). 


\section{A SECOND LOOK AT ETHNIC DIFFERENCES IN EDUCATIONAL ATTAINMENT}

This study started out from three competing hypotheses on the nature of ethnic inequalities in education. One theoretical possibility is that class disadvantage mostly or fully explains the persistence of ethnic disadvantage in the next generation. Combining the empirical literature on persistent class inequality with evidence of intergenerational integration in US-based research on the second generation, one would indeed expect that direct effects of ethnic origins on the attainment of the next generation are small or negligible. Alternatively, in case of cumulative disadvantage, ethnic and class disadvantage would add up in the sense that they both contribute significantly to persistent disadvantage in the next generation. A third possibility is ethnic advantage, when ethnicity would counteract the impact of parental class disadvantage on the next generation. Taking an approach from the theory of intergenerational resource investment, the analysis distinguishes various sorts of parental resources, which are known to vary with ethnicity and with social class. The underlying assumptions are that ethnicity and class are associated with distinct bundles of resources within families; and that families accumulate and invest resources primarily to improve the life chances of the next generation. Hence our key question: which parental resources are helping or hindering the children of migrant workers to stay on and succeed in school?

One way to answer this question is to decompose ethnic differences in educational attainment by adding theoretically relevant family-based resources. The three graphs in Figure 1 show the odds of a university degree, of vocational training, and of not completing secondary school (as compared with middle-level types of full secondary education). The figures indicate the odds of Moroccan, Italian, Turkish and other minority groups getting each of these qualifications rather than upper secondary (middlelevel) qualifications, relative to those of the non-minority reference group. Dark grey bars to the left indicate gross ethnic differences in Model 1. From left to right, the figures show changes in these odds ratios when parental class, education and material disadvantage or housing are added to the model. The white bars to the right indicate the remaining ethnic differences in the final model, with additional controls for more recently migrated parents and incomplete families.

Focusing on the top end of the attainment range, most ethnic disadvantage by far is found for the odds of attaining university degrees (Figure 1(a)). Thus, the odds of Turks and Moroccans obtaining a university degree (rather than middle-level types of secondary education) are only one-fifth of those of their non-minority peers. Taking into account the occupation and education of the parents in 1991, this gross ethnic disadvantage is much 
(a) Odds of university degree (vs. full secondary education) in 2001

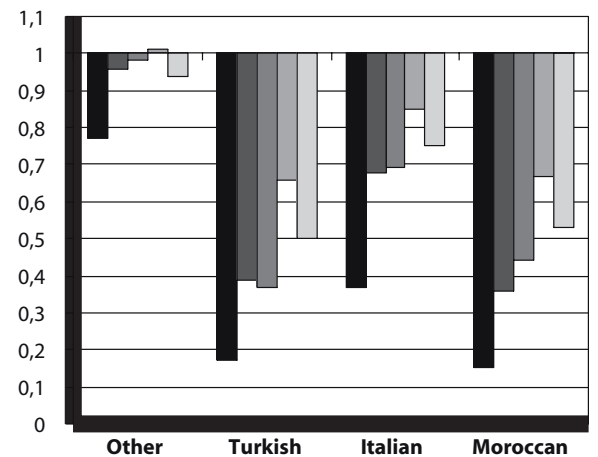

Ethnic origin

$\square$ Parent class 1991

$\square$ Parent educucation 1991

$\square$ Economic disadvantage 1991

$\square$ Migration + family 1991

(b) Odds of vocational (vs. other) secondary education in 2001

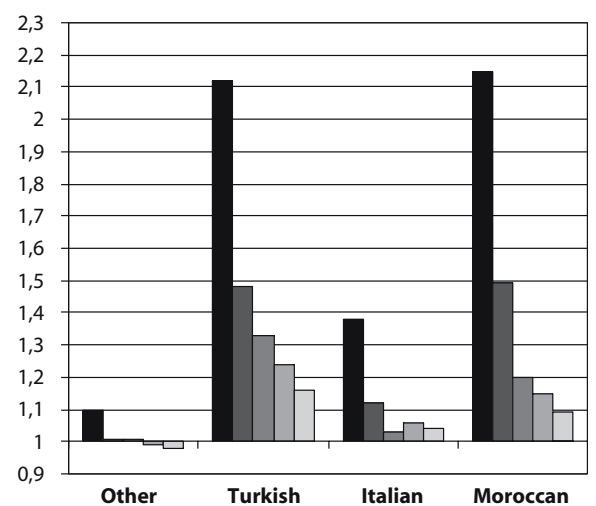

(c) Odds of less than full secondary education in 2001

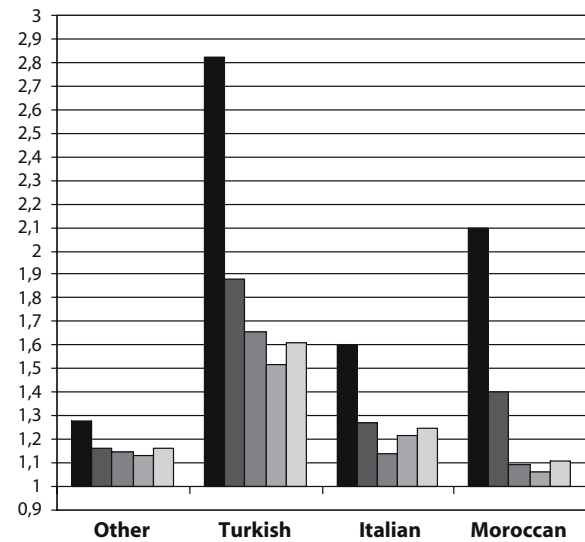

Ethnic origin

$\square$ Parent class 1991

$\square$ Parent educucation 1991

$\square$ Economic disadvantage 1991

$\square$ Migration + family 1991

Figure 1 Gross and net ethnic educational disadvantage: Odds of tertiary, secondary and lower qualifications for ethnic minorities in Models 1-5 
reduced. Still, the odds of Turks and Moroccans obtaining a university degree are less than half those of their non-minority peers with a similar class background. Except for the Moroccan case, parental qualifications do not reduce ethnic differences further once parental occupations are accounted for. The inclusion of housing conditions as an indicator of the material wealth of one's family in the fourth model results in a dramatic further reduction of ethnic differences. Now, the odds of Turks and Moroccans obtaining a university degree are around two-thirds of those of non-minority peers, while Italians are close to achieving parity with nonminority peers whose parents had similar occupations, qualifications and living standards. Interestingly, adding controls for family composition and recent migration slightly increases ethnic differences in attainment again. In light of the more traditional family patterns of ethnic minorities, however, the reference group in this last model is a rather atypical selection of relatively disadvantaged yet complete non-minority households. Overall, the analysis confirms the cumulative ethnic and class disadvantage of the Turkish and Moroccan groups.

Turning to the bottom end of the attainment spectrum, there is again evidence of a clear overall ethnic disadvantage in Belgium (Figure 1(b)). The odds of Turks and Moroccans leaving school with vocational qualifications (rather than the middle level) are more than twice those of their nonminority counterparts, while the odds for Italians are almost one and a half times those of their non-minority peers. Whereas the Italian disadvantage virtually disappears as soon as parental occupations are added to the model, the figure shows a stepwise reduction of Turkish and Moroccan disadvantage with the inclusion of parental occupations, qualifications and wealth to become insignificant in the final model. By and large, the class background of ethnic minority families, and the related lack of relevant resources, fully explains the over-representation of the second generation in vocational training.

Along similar lines, ethnic minorities are much more exposed to the risk of leaving school without full secondary qualifications (Figure 1(c)). The odds of Turks leaving school with less than full secondary education (rather than middle-level secondary) are almost three times those of their non-minority peers; for Moroccans the odds are twice, and for Italians one-and-a-half times, those of non-minority peers. Again, gross ethnic disadvantage is much reduced with the introduction of occupational class, and the inclusion of parental education and wealth further reduces ethnic disadvantage. In the final model, net ethnic differences in dropout risks are no longer significant, except for the Turkish minority group. The odds of Turks not completing secondary school are still more than one-and-ahalf times those of non-minority peers. Clearly then, Turkish young adults are least inclined to stay on in school after the age of compulsory education. 


\section{CONCLUSION}

To summarize, parental resources appear to be very powerful explanatory variables for ethnic minority and non-minority people alike. The stepwise models are a first attempt to decompose the (lack of) family-based resources attached to ethnic minority status in Belgium. The results give a more precise account of the causes and forms of educational inequality than there was hitherto available. For the most part, the educational disadvantage of ethnic minorities persists due to the lack of relevant resources in the first generation of migrant workers. This is evident from the general and large impact of parental education on the attainment of their children. In addition, the economic disadvantage of low-income families also affects the school careers of minority children, as shown by the effects of housing. The predominant working-class profile of minority families, as well as the high rate of unemployment and inactivity, contributes further to the educational disadvantage of the next generation. In most cases, the effects of ethnicity on final attainment are no longer significant when parental social background is taken into account. Importantly, the absence of significant class by ethnicity interactions suggests that the social background of the parents influences the educational attainment of minority and nonminority students in much the same way.

Nevertheless, the role of class origins in the educational attainment of ethnic minorities should be interpreted with due caution. Thus, the class origins of immigrants refer to distinct class structures in the sending societies, from which they were originally selected. In addition, the class positions of immigrant workers in the receiving society are determined in part by their ethnic minority status. Moreover, there is evidence of cumulative disadvantage for Turkish and Moroccan minorities in Belgium, with an additional ethnic disadvantage that is not accounted for by the socioeconomic resources of the parents. This is most clearly the case for the Turkish minority. To a lesser extent, cumulative ethnic and class disadvantage is also found for the Moroccan minority. In terms of educational outcomes, the top end and the bottom end of the attainment spectrum, which are most unequal in terms of the class background of students, are also more unequal in terms of their ethnic origins. At the bottom end, working-class children in general are less protected against dropping out of school without completing secondary education, and Turks even less so. At the top end, university degrees, which have largely remained the privilege of the middle and upper classes, are also least accessible to ethnic minorities, in particular Turks and Moroccans. Only Turks are also less able to obtain lower tertiary qualifications than other young people from similar social backgrounds. Finally, the unexplained ethnic gap in tertiary education is even larger in Flanders than in the rest of the country. As Flemish schools 
more readily (re-)orient students with lower grades to vocational tracks than Francophone schools, they tend to perpetuate the initial educational disadvantage of ethnic minorities into their subsequent school careers. Importantly, significant region by ethnicity interactions show that we should look beyond the formal structure of the education system in order to understand the ways in which local tracking practices affect the school careers of ethnic minorities.

Further research is needed to find out to what extent the additional ethnic disadvantage of Turks and Moroccans in Belgium is a matter of institutional discrimination, unmeasured differences in cultural resources, or educational under-investment by Turkish or Moroccan families. At this stage of the analyses, the pattern of findings suggests three preliminary conclusions. First, the socioeconomic exclusion of migrant workers, as indexed by their education, housing and employment situation (in this order of importance), goes a long way to explain the persistence of ethnic inequalities in education. Second, the most sizeable cumulative ethnic and class inequalities are found in tertiary education, which is still largely reserved for the children of the local middle and upper classes. Third, most unexplained ethnic disadvantage is found for the Turkish minority and in the Flemish region. In combination with earlier findings, the most dramatic ethnic disadvantage of Turks in Flanders is suggestive of a double explanatory mechanism. On the one hand, the record rates of ethnic segregation and ethnic language retention of Turkish families, and particularly the lack of fluency in French or Dutch of Turkish parents (cf. Lesthaege, 2000), are likely to hamper the school achievement of Turkish pupils during compulsory education. From their side, Belgian schools with their hierarchical tracking structure, and particularly the tracking practices of Flemish schools (cf. Ouali and Réa, 1994), tend to preclude Turkish participation in tertiary education through the early selection of pupils with learning or language problems into special vocational tracks. More research is needed, however, on the interplay of language barriers and tracking practices in the school careers of ethnic minorities.

\section{Notes}

1 Not counting intermarriage between new migrants and naturalized partners of the same ethnic ancestry, about 6 percent of all young adults have mixed parentage. Since mixed marriages were very rare among the first generation of Turkish and Moroccan origin, young adults of mixed parentage are included in the residual category of 'other or mixed origin'.

2 For young adults who are still full-time students in 2001, their educational attainment refers to the highest level of education completed, rather than to the level currently attended. 


\section{References}

Alba, R. and V. Nee (2003) Remaking the American Mainstream: Assimilation and Contemporary Immigration. Cambridge, MA: Harvard University Press.

Alba, R., J. Handl and W. Müller (1994) 'Etnische Ungleichheit im Deutschen Bildungssystem' (Ethnic inequality in the German education system), Köllner Zeitschrift für Soziologie und Sozialpsychologie 46: 209-37.

Boudon, R. (1974) Education, Opportunity and Social Inequality. New York: Wiley.

Britten, N. and A. Heath (1983) 'Women, Men and Social Class', in E. Gamarnikow, D. Morgan, J. Purvis and D. Taylorson (eds) Gender, Class and Work, pp. 46-60. London: Heinemann Educational Books.

Chiswick, B.R. and P.W. Miller (1998) 'Language Skill Definition: A Study of Legalized Aliens', International Migration Review 32: 877-900.

Eggerickx, T., C. Kesteloot and M. Poulain (1999) 'De allochtone bevolking in België' (The population of migrant origin in Belgium), Censusmonographs, Vol. 3. Brussels: National Institute of Statistics.

Esser, H. (2004) 'Does the New Immigration Require a New Theory of Intergenerational Integration?', International Migration Review 38: 1126-59.

Feliciano, C. and R.G. Rumbaut (2005) 'Gendered Paths: Educational and Occupational Expectations and Outcomes among Adult Children of Immigrants', Ethnic and Racial Studies 28(6): 1087-118.

Kalmijn, M. and G. Kraaykamp (1996) 'Cultural Capital, Race and Schooling: An Analysis of Trends in the US', Sociology of Education 69: 22-34.

Lareau, A. and E. MacNamara Horvat (1999) 'Moments of Social Inclusion and Exclusion: Race, Class and Cultural Capital in Family-School Relationships', Sociology of Education 72: 37-53.

Lesthaeghe, R., ed. (2000) Communities and Generations: Turkish and Moroccan Populations in Belgium. Brussels: VUB Press.

Marks, G.M. (2006) 'Accounting for Immigrant-Non-immigrant Differences in Reading and Mathematics in 20 Countries', Ethnic and Racial Studies 28(5): 925-946.

Modood, T. (2004) 'Capitals, Ethnic Identity and Educational Qualifications', Cultural Trends 13(2): 87-105.

Neels, K. (2000) 'Education and the Transition to Employment: Young Turkish and Moroccan Adults in Belgium', in R. Lesthaeghe (ed.) Communities and Generations: Turkish and Moroccan Populations in Belgium, pp. 243-77. Brussels: VUB Press.

Ouali, N. and A. Réa (1994) 'La scolarité des élèves d'origine étrangère' (The schooling of pupils of foreign origin), Cahiers de Sociologie et d'Economie Régionales 21-22: 7-56.

Phalet, K. (2007) 'Down and Out: The Children of Migrant Workers in the Belgian Labour Market', in A. Heath and S.-Y. Cheung (eds) Unequal Chances: Ethnic Minorities in Western Labour Markets, pp. 143-80. Oxford: Oxford University Press.

Phalet, K. and M. Swyngedouw (2003) 'Measuring Immigrant Integration: The Case of Belgium', Studi Emigrazione/Migration Studies 40(152): 773-803.

Portes, A. and M. Zhou (1993) 'The New Second Generation: Segmented 
Assimilation and its Variants among Post-1965 Immigrant Youth', Annals of the American Academy of Sciences 530: 74-96.

Rothon, C. (2005) 'Black and Minority Ethnic Educational Attainment and Engagement with School in Britain', Sociology DPhil thesis, Oxford University.

Shavit, Y. and H-P. Blossfeld (eds) (1993) Persistent Inequality: Changing Educational Attainment in Thirteen Countries. Boulder, CO: Westview Press.

Vallet, L.-A. and J.-P. Caille (1996) Les élèves étrangers ou issues de l'immigration dans l'école et le collège français, volumes I, II et III (Foreign pupils or issues of immigration in French schools and colleges). Documents de Travail INSEE/CREST, 9614, 9615 et 9616. Paris: INSEE.

Zhou, M. and C.L. Bankston (1998) Growing up American: How Vietnamese children Adapt to Life in the US. New York: Russell Sage Foundation.

KAREN PHALET is Professor in Social Psychology in the Faculty of Psychology and Educational Sciences at the University of Leuven and a Senior Research Fellow of Ercomer (European Research Center On Migration and Ethnic Relations) at the Universities of Utrecht and Leuven. Address: ERCOMER/LESP, University of Leuven, Tiensestraat 102, B-3000 Leuven, Belgium. [email: K.Phalet@fss.uu.nl; Karen.Phalet@psy. kuleuven.be]

PATRICK DEBOOSERE is a Senior Researcher in Demography in the Department of Social Research at the Free University of Brussels. Address: Vakgroep Sociaal Onderzoek,VUB, Pleinlaan 2, B-1050 Brussels, Belgium. [email:Patrick.Deboosere@vub.ac.be]

VICKY BASTIAENSSEN is a PhD student in Demography in the Department of Social Research at the Free University of Brussels. Address: Vakgroep Sociaal Onderzoek,VUB, Pleinlaan 2, B-1050 Brussels, Belgium. [email:Vicky.Bastiaenssen@vub.ac.be] 


\section{APPENDIX}

This appendix contains two tables and three figures that are discussed earlier in the article. Table A1 specifies stepwise multinomial regression models and indicates the improvement of model fit for each step. Table A2 shows the parameter estimates for the final model.

Table A1 Stepwise multinominal regressions of educational attainment in 2001: Model fit and estimated explained variance (Cox and Snell pseudo $R^{2}$ )

\begin{tabular}{lccccc}
\hline & Model 1 & Model 2 & Model 3 & Model 4 & Model 5 \\
\hline $\begin{array}{l}\text { Ethnicity, gender, age and } \\
\text { region }\end{array}$ & $\mathrm{X}$ & $\mathrm{X}$ & $\mathrm{X}$ & $\mathrm{X}$ & $\mathrm{X}$ \\
$\begin{array}{l}\text { + Parental class 1991 } \\
\text { + Parental educ. 1991 }\end{array}$ & & $\mathrm{X}$ & $\mathrm{X}$ & $\mathrm{X}$ & $\mathrm{X}$ \\
+ Parental housing 1991 & & & $\mathrm{X}$ & $\mathrm{X}$ & $\mathrm{X}$ \\
+ Parental migration, both & & & & $\mathrm{X}$ & $\mathrm{X}$ \\
parents present 1991 & & & & & $\mathrm{X}$ \\
$\begin{array}{l}\text { Model fit } \\
N=61.562\end{array}$ & $\mathrm{Chi}(40)=$ & $\mathrm{Chi}^{2}(55)=$ & $\mathrm{Chi}^{2}(70)=$ & $\mathrm{Chi}^{2}(85)=$ & $\mathrm{Chi}^{2}(95)=$ \\
(9187 missing values) & 4.805 & 12.939 & 18.683 & 20.072 & 20.169 \\
& $R^{2}=.08$ & $R^{2}=.19$ & $R^{2}=.26$ & $R^{2}=.28$ & $R^{2}=.28$ \\
\hline
\end{tabular}

Note: In each step interactions with ethnicity were tested so as to make sure that main effects were replicated across ethnic origin groups. There were no significant interactions for gender, age, parental class and education, parental family situation and migration cohort. Only the interactions of region and housing by ethnicity were significant, suggesting. greater educational disadvantage for ethnic minorities in Flanders and less educational advantage associated with home ownership in ethnic minority households. 


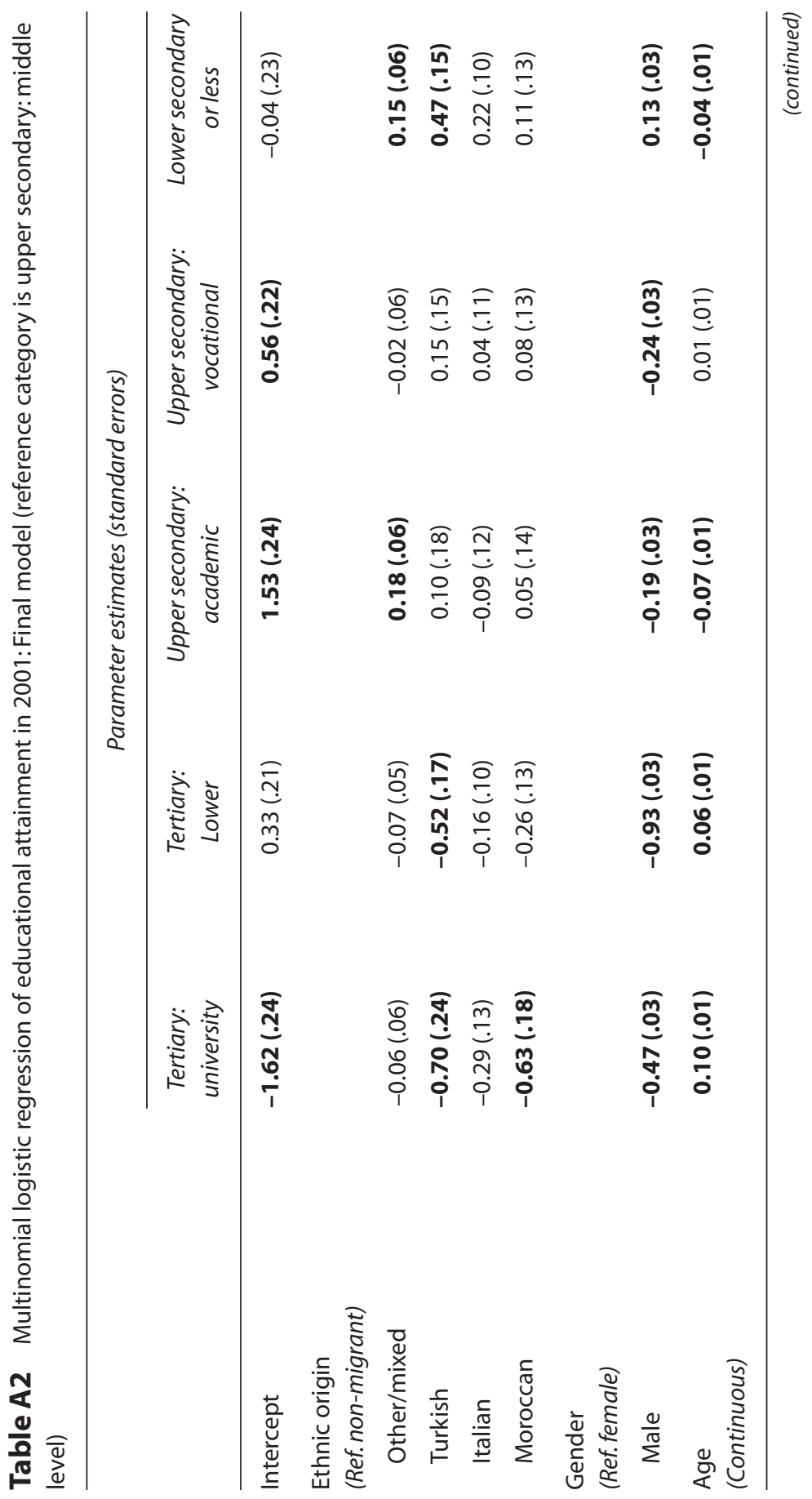




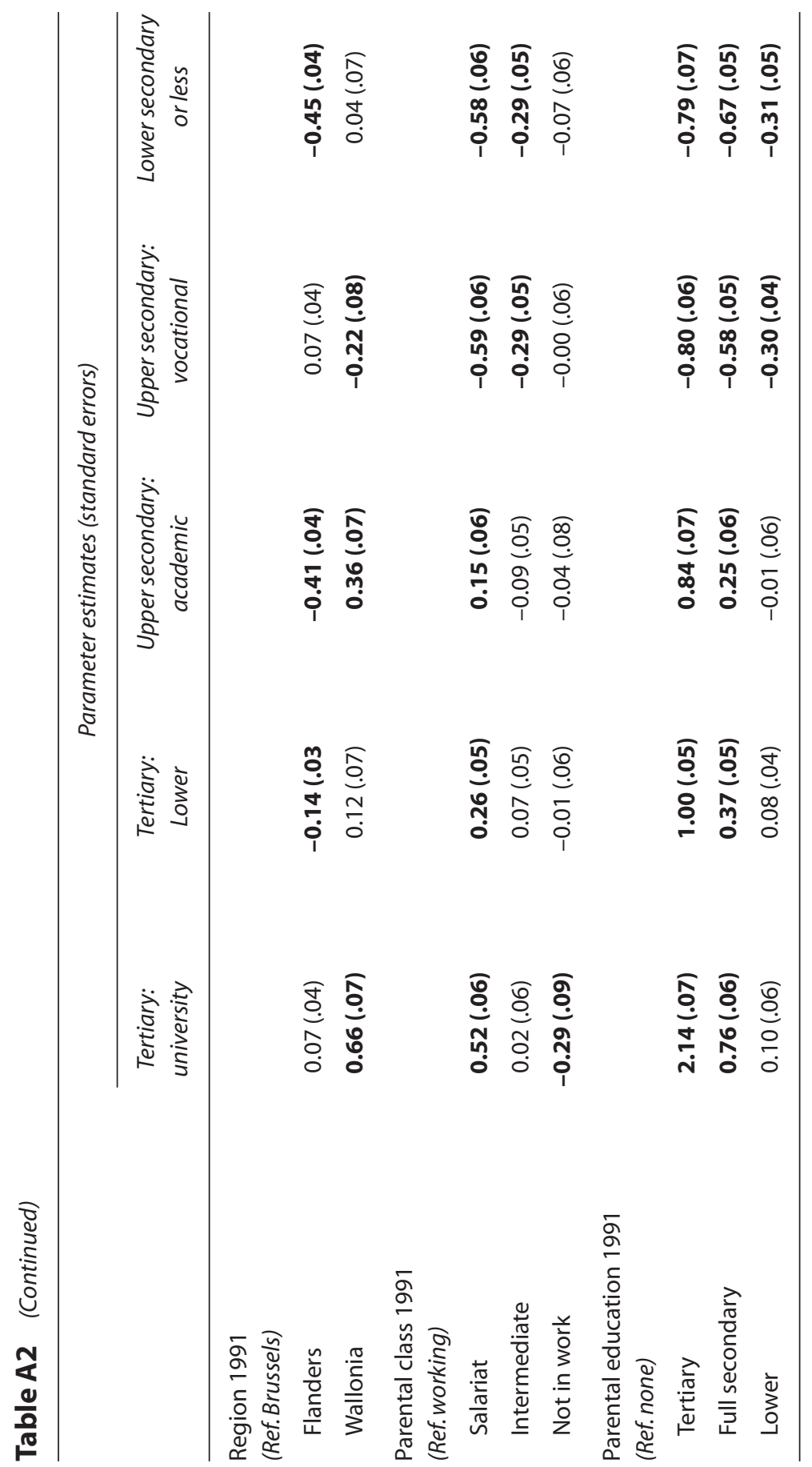




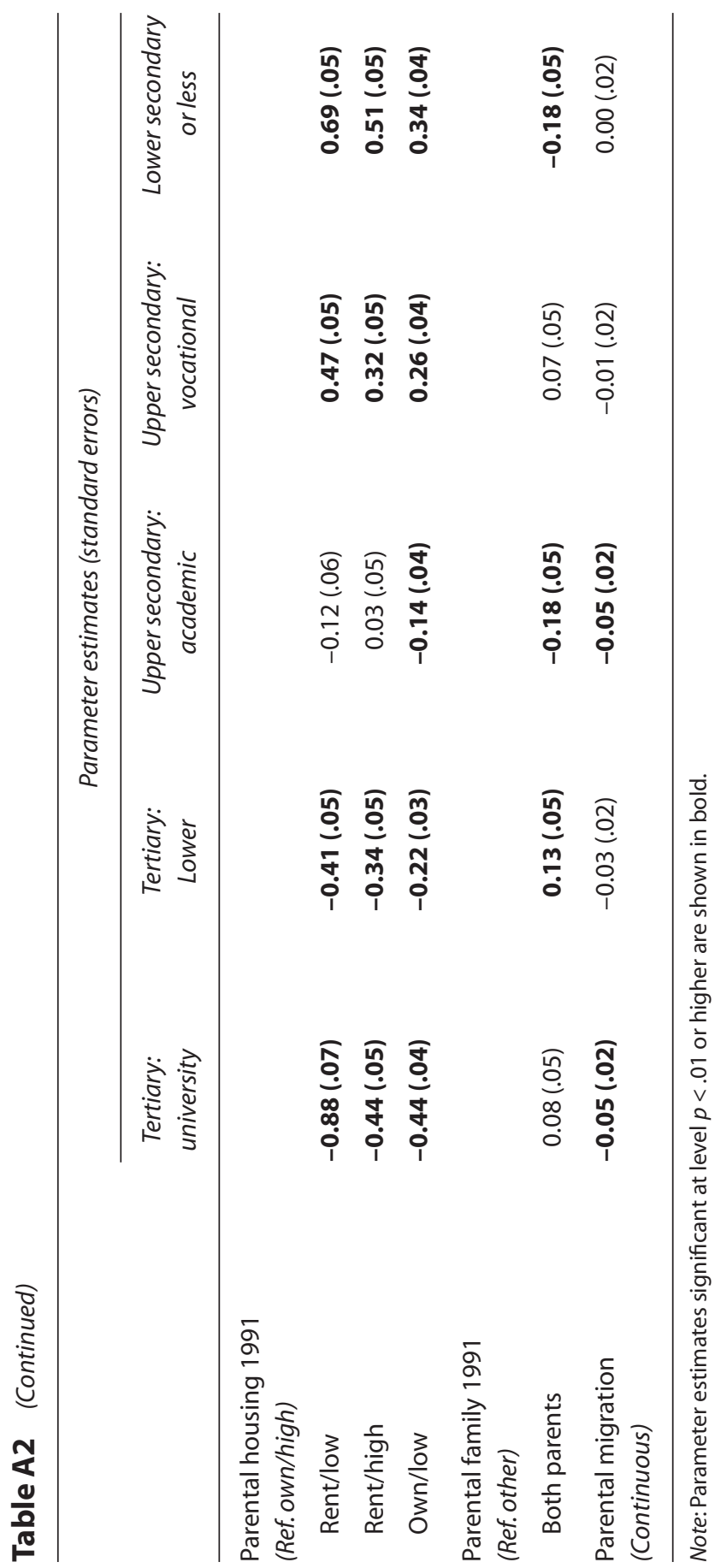

